\title{
Shrub canopy removal influences community assembly processes in shrub-encroached grassland in the Inner Mongolia steppe, China
}

\author{
Ke Dong ${ }^{1}$, YuJuan $\mathrm{Xu}^{1}$, Guang $\mathrm{Hao}^{1}$, Xinfeng Ding ${ }^{1}$, JinLong Wang ${ }^{2}$, Xingdong $\mathrm{He}^{1}$, Lei \\ Chen $^{1}$, Nianxi Zhao ${ }^{1}$, and Yubao Gao ${ }^{1}$ \\ ${ }^{1}$ Nankai University \\ ${ }^{2}$ Tianjin Agricultural University
}

July 9, 2020

\begin{abstract}
Understanding community assembly mechanism is essential for us to predict community dynamics and restoration process in the context of intensive human activities. In this study, we aimed to explore how the removal of shrub canopy influenced the community assembly in shrub-encroached grassland by both trait-based and phylogenetic approaches. We carried out an experiment of shrub canopy removal with three frequencies (no removal, removal once and twice a year) in a shrub-encroached grassland in China. We investigated community species composition under each treatment and collected plant functional traits for each species. We calculated the standard effect size (SES) of phylogenetic and trait-based functional diversity based on null model analysis to determine the dominant community assembly process. By phylogenetic analysis, the random process drove the community assembly, being independent of the removal frequencies and locations; while by trait-based approach, random process dominated the assembly in communities under 'no removal' treatment beneath shrub and under 'removal twice a year' treatment in shrub-interspace when using some certain single traits, and the limiting similarity process dominated the assembly in the rest communities. Removal of shrub canopy twice a year released more niches which promoted the performance of herbaceous species beneath shrub and promoted the settlement of annuals in shrub-interspace. Compared with phylogenetic analysis, the results of trait-based approach were more sensitive to the human activities. All these findings indicated that removal of shrub canopy twice a year would be an effective way for the restoration of shrub-encroached grassland.
\end{abstract}

\section{Hosted file}

Manuscript.docx available at https://authorea.com/users/322089/articles/468310-shrub-canopyremoval-influences-community-assembly-processes-in-shrub-encroached-grassland-in-theinner-mongolia-steppe-china 

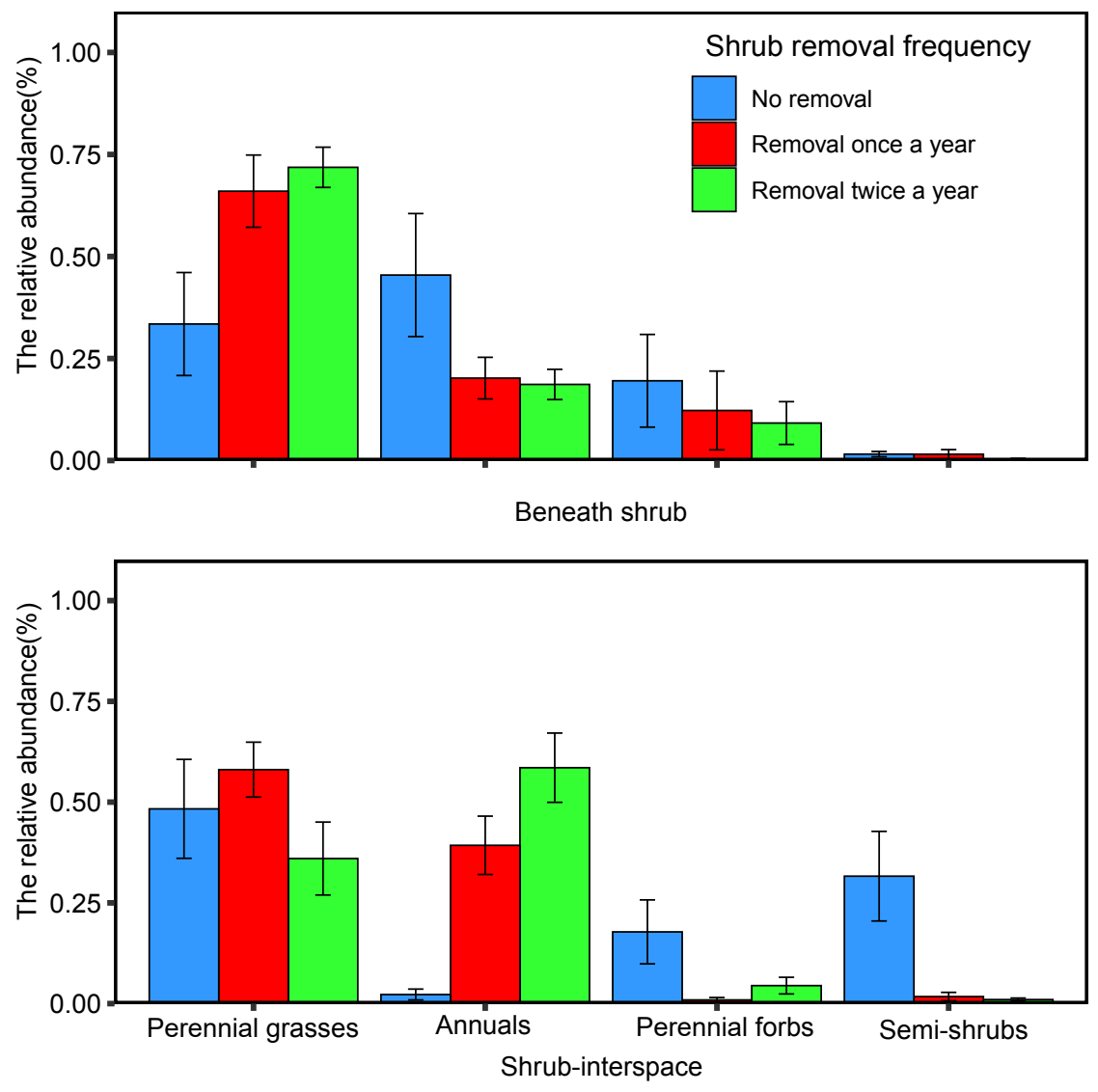

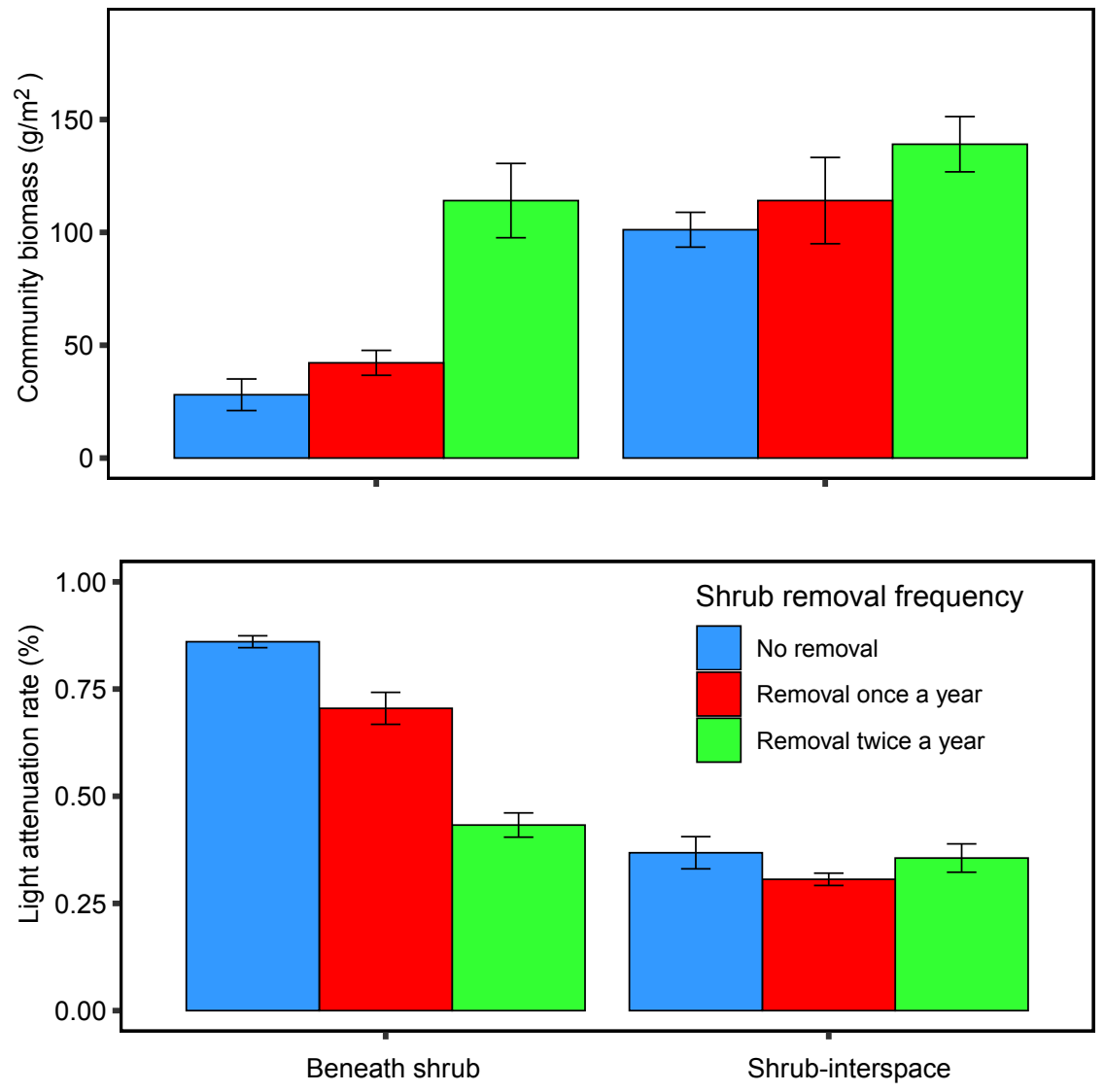


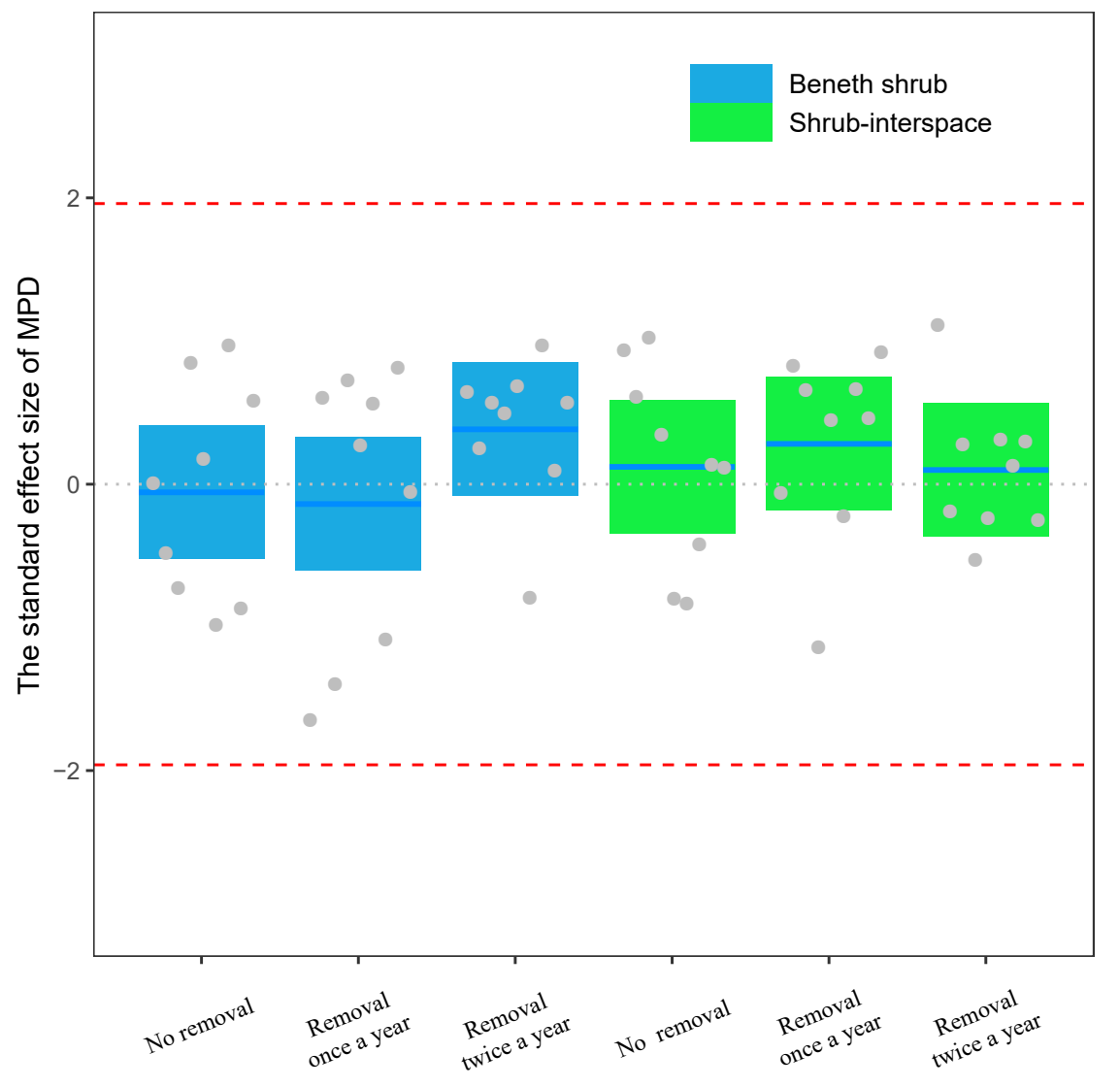



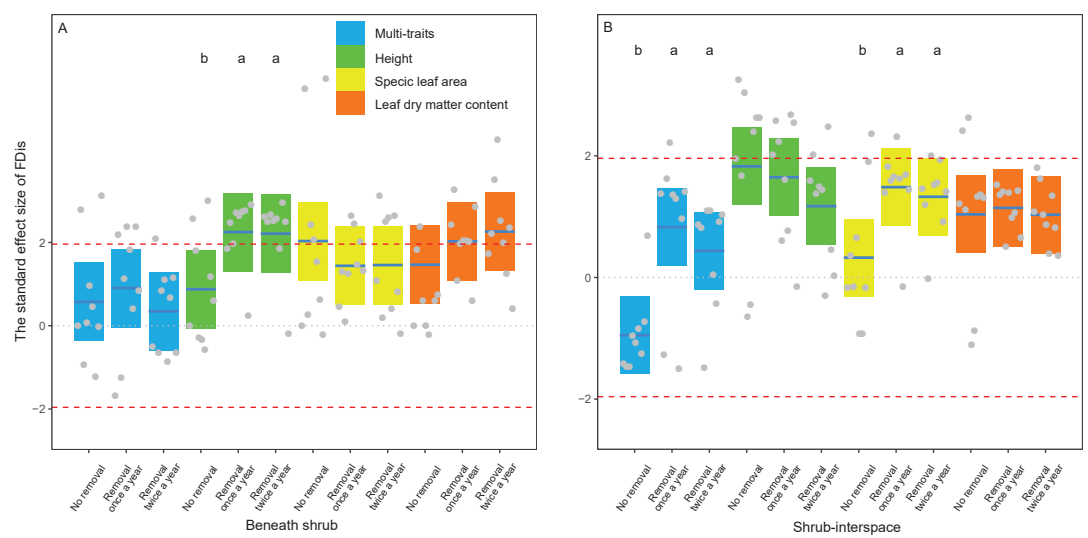